\title{
The effects of 7-nitroindazole on serum neuron-specific enolase and astroglia-derived protein (S100ß) levels after traumatic brain injury
}

\author{
NAN DONG, YI DIAO, MAOHUA DING, BAOQIANG CAO and DEHUAJIANG \\ Department of Neurosurgery, Xuzhou Central Hospital, Xuzhou, Jiangsu 221009, P.R. China
}

Received May 30, 2016; Accepted November 14, 2016

DOI: $10.3892 /$ etm.2017.4411

\begin{abstract}
We investigated the possible role of 7-nitroindazole (7-NI) in regulating serum neuron-specific enolase (NSE) and S100 $\beta$ levels in a rat model of traumatic brain injury (TBI). We also explored the possible mechanism by which 7-NI may affect the level of NSE and S100 $\beta$. A total of 160 healthy adult male Sprague-Dawley rats were randomly divided into 2 groups: i) The saline-treated group and ii) the 7-NI-treated group. Using the random number table, the groups were further divided into four subgroups: i) The sham-injured group; ii) the TBI $6 \mathrm{~h}$ group; iii) the TBI $12 \mathrm{~h}$ group; and iv) the TBI 24 h group $(n=20)$. Controlled cortical impact in rats was established. Serum NSE and S100 $\beta$ levels, nitric oxide (NO) level, water content, Evans blue (EB) content, malondialdehyde (MDA) level and total superoxide dismutase (T-SOD) level in the brain tissue were measured. NO synthase (NOS) activity was measured at 6,12 and $24 \mathrm{~h}$ after TBI. Pathological changes in brain tissue were studied by hematoxylin and eosin (H\&E) staining at each time-point. NSE and S100 $\beta$ levels, NO content, water content, EB content and MDA level in the brain tissue increased significantly after TBI. NOS activity was also increased significantly after TBI while T-SOD content in brain tissue was significantly reduced after TBI. H\&E staining showed that brain damage was aggravated gradually after TBI. We concluded that the early application of 7-NI significantly reduced serum NSE and S100 $\beta$ levels after TBI. The neuroprotective effects of 7-NI may be associated with reduced NOS activity, reduced NO content, alleviated brain edema, lower blood-brain barrier permeability and oxidative stress. Serum NSE and S100 $\beta$ levels can reflect the therapeutic effect of 7-NI, which suggest a good diagnostic value.
\end{abstract}

Correspondence to: Dr Dehua Jiang, Department of Neurosurgery, Xuzhou Central Hospital, 199 Jiefang Road, Xuzhou, Jiangsu 221009, P.R. China

E-mail: jingdehua1963@163.com

Key words: traumatic brain injury, 7-nitroindazole, nitric oxide, nitric oxide synthase, neuron-specific enolase, $\mathrm{S} 100 \beta$, oxidative stress

\section{Introduction}

Traumatic brain injury (TBI) is the most important cause of mortality and disability among young individuals. The sequelae from severe TBI can bring serious consequence and heavy burden to the society and the family (1). Results obtained from prior studies on the rat TBI model showed that nitric oxide (NO) and neuronal NO synthase (nNOS) played an important neurotoxicity role in the early stage of TBI, while the application of nNOS inhibitor 7-nitroindazole (7-NI) played a neuroprotective role in early and medium stages of TBI by significantly reducing the brain nNOS activity and NO content (2). Changes in the levels of neuron-specific enolase (NSE) and astroglia-derived protein (S100 $\beta$ ) have been shown to be closely related to the severity of TBI (3). It has been reported that combined detection of NSE and S100 $\beta$ after TBI can be taken as a sensitive indicator to judge the severity of TBI and prognosis (3).

To the best of our knowledge, studies on possible influence of 7-NI on NSE and S100 $\beta$ levels after TBI have been rarely reported. We, in this study, investigated the influence of 7-NI on quantitative changes of NSE and S100 $\beta$ after TBI. We also explored the possible mechanism by which 7-NI may affect the level of NSE and S100 $\beta$.

\section{Materials and methods}

Experimental animals and grouping. One hundred sixty adult male Sprague-Dawley rats, weighing 280-320 g, were purchased from the Experimental Animal Center of Nanjing Medical University. The rats were kept in a temperaturecontrolled room $\left(21 \pm 2^{\circ} \mathrm{C}\right)$ and had access to water and food. The rats were randomly divided into the normal saline treatment group and the 7-NI treatment group. Each large group was randomly divided into four sub-groups: The sham operation group, the TBI $6 \mathrm{~h}$ group, the TBI $12 \mathrm{~h}$ group and the TBI $24 \mathrm{~h}$ group, with 20 rats in each group.

Main reagents and instruments. Evans blue (EB), 7-NI and formamide were purchased from Sigma-Aldrich (St. Louis, MO, USA). NSE and S100 $\beta$ enzyme-linked immunosorbent assay (ELISA) kits were purchased from (Cayman Chemical Co., Ann Arbor, MI, USA); NOS assay kit was provided from Nanjing Jiancheng Bioengineering Institute (Nanjing, China); 
lipid oxidation malondialdehyde (MDA) kit and total superoxide dismutase (T-SOD) activity assay kit was purchased from Beyotime Institute of Biotechnology (Shanghai, China); PinPoint $^{\mathrm{TM}}$ cortical impactor was purchased from Hatteras Instruments, Inc. (Cary, NC, USA); and the stereotaxic apparatus was purchased from RWD Life Science Co., Ltd. (Shenzhen, China). Approval for the animal studies was received from the Animal Ethics Committee of Xuzhou Medical University Animal Center.

Establishment of rate controlled cortical impact (CCI) model. Rat CCI models of moderate brain injury were established referring to the production methods of rat CCI model explained by Fukushima et al (4). Chloral hydrate (10\%) was injected to abdominal cavity for anesthesia $(3 \mathrm{ml} / \mathrm{kg}$ ). Rats were fixed on a stereotactic apparatus in prone position. Routine disinfection was carried out, the incision in the middle of scalp was made with a length of $\sim 2.5 \mathrm{~cm}$, the left periosteum was separated and the skull was exposed. A 2-mm incision was made bedside the sagittal suture which was $\sim 2 \mathrm{~mm}$ behind the left coronal suture and the bone window had a diameter of $\sim 5 \mathrm{~mm}$. We maintained the integrity of the cerebral dura mater. The sterilized impactor head (diameter, $4 \mathrm{~mm}$ ) was set within the bone window and close to the cerebral dura mater. We used the following impact parameters: Impact velocity was $4 \mathrm{~m} / \mathrm{sec}$, impact depth was $2 \mathrm{~mm}$ and contact time was $250 \mathrm{msec}$. Rats were under apnea for a few seconds and short limbs twitch after the impact. After the recovery of spontaneous breathing, sterile bone wax was used to seal the bone window and suture the scalp. During and after operation, constant temperature was maintained with rectal temperature between 36.5 and $37.5^{\circ} \mathrm{C}$. Rats in the 7-NI treatment group was injected with $25 \mathrm{mg} / \mathrm{kg}$ of 7-NI in abdominal cavity within $1 \mathrm{~h}$ after the operation, and the normal saline treatment group received $3 \mathrm{ml} / \mathrm{kg}$ of normal saline after operation.

Serum NSE and S100 $\beta$ protein levels. Thoracotomy was carried out after anesthesia at different time-points (5 rats were randomly selected from each group). In the sham operation group, thoracotomy was carried out within $6 \mathrm{~h}$ after operation and 3-ml arterial blood was taken from the left ventricle and centrifuged at 2,500 x g for $10 \mathrm{~min}$. Supernatant was collected, and stored at $-20^{\circ} \mathrm{C}$. Double-antibody sandwich ELISA was used to determine the levels of NSE and S100 $\beta$ proteins in the serum. We closely followed the instruction provided by the ELISA kit manufacturer (Cayman Chemical Co.).

Brain tissue NO content and NOS activity determination. Five rats were randomly selected from remaining rats in each group and were decapitated rapidly after anesthesia at each time-point. Edema cortex tissue around the injury lesion was quickly separated $(100 \mathrm{mg})$ and $1 \mathrm{ml}$ pre-cooled $\left(4^{\circ} \mathrm{C}\right)$ phosphate-buffered saline (PBS) buffer was added. Tissue was then homogenized into $10 \%$ tissue homogenate on the ice and centrifuged at $4^{\circ} \mathrm{C}$ at $10,500 \mathrm{x} \mathrm{g}$ for $20 \mathrm{~min}$, and the supernatant was collected and stored at $-20^{\circ} \mathrm{C}$. NO content and NOS activity in brain tissue samples were measured in strict accordance with the manufacturer's instructions. NOS activity was defined as: $1 \mathrm{mg}$ of tissue protein could generate $1 \mathrm{nmol}$ NO per minute as an activity unit.
Determination in the brain tissues water content. After completion of blood collection, $4^{\circ} \mathrm{C}$ pre-cooled PBS buffer was immediately injected via left ventricle until the supernatant flowed from the right ventricle. The cerebral hemisphere at the impact side was taken after craniotomy, after being accurately weighed and recorded. Solution was placed in $70^{\circ} \mathrm{C}$ oven for $72 \mathrm{~h}$ and then the dry weight was measured. Brain tissue water content was calculated using the formula: Water content $=($ wet weight - dry weight)/wet weight x $100 \%$.

Brain tissue blood-brain barrier $(B B B)$ permeability. Five rats were randomly selected from the remaining rats in each group and were injected with $2 \mathrm{ml} / \mathrm{kg}$ of $2 \% \mathrm{~EB}$ via the femoral vein $2 \mathrm{~h}$ before sacrifice. Thoracotomy was carried out under anesthesia after $2 \mathrm{~h}$. A $4^{\circ} \mathrm{C}$ pre-cooled PBS buffer was injected via the left ventricle until the supernatant volume flowed from the right ventricle. Brain was removed after decapitation, the cerebral cortex at injured side was separated and placed in the test tube after the wet weight was accurately measured and then $3 \mathrm{ml}$ formamide was added and it was placed in water bath at $37^{\circ} \mathrm{C}$ for $48 \mathrm{~h}$. It was then centrifuged at 2,500 $\mathrm{x} \mathrm{g}$ for $15 \mathrm{~min}$ and supernatant was collected and the light absorption was measured at $620 \mathrm{~nm}$ wavelength.

Brain tissue MDA and T-SOD content. After the rats were sacrificed, $100 \mathrm{mg}$ of edema cortex tissue around the injury lesion was quickly separated, $1 \mathrm{ml}$ pre-cooled PBS buffer $\left(4^{\circ} \mathrm{C}\right)$ was added and it was homogenized into $10 \%$ tissue homogenate on ice. It was then centrifuged at 1,600 x $\mathrm{g}$ for $10 \mathrm{~min}$ at $4^{\circ} \mathrm{C}$, and supernatant was collected and stored at $-20^{\circ} \mathrm{C}$. Subsequently, MDA and T-SOD contents in the brain tissue were determined using thiobarbituric acid method and xanthine enzyme method respectively, as per the manufacturer's instructions.

Pathological observation. Thoracotomy was carried out on the remaining rats in each group under anesthesia at the corresponding time-point. A $4^{\circ} \mathrm{C}$ pre-cooling PBS buffer was injected via the left ventricle until the supernatant volume flowed from the right ventricle, and then $4^{\circ} \mathrm{C}$ pre-cooling $4 \%$ formaldehyde was injected for fixation. After craniotomy, rat brains were collected and sucrose was used for gradient dehydration. Regular paraffin was used for packing, and $5-\mu \mathrm{m}$ sections were cut. After dewaxing, the hematoxylin and eosin (H\&E) staining was carried out, and samples were observed under light microscopy.

Statistical analysis. SPSS 19.0 statistical software (Chicago, IL, USA) was used for statistical analysis. Drawings were made by GraphPad Prism 5 software (GraphPad Software Inc., San Diego, CA, USA). The data were expressed as mean \pm SD and the pairwise comparison was made with t-test. $\mathrm{P}<0.05$ was considered to indicate a statistically significant difference.

\section{Results}

Changes in serum NSE and S100 $\beta$ protein levels. Serum NSE protein level after TBI in the normal saline treatment and the 7-NI treatment groups were gradually increased over time and reached a peak at $24 \mathrm{~h}$. In two groups, serum 

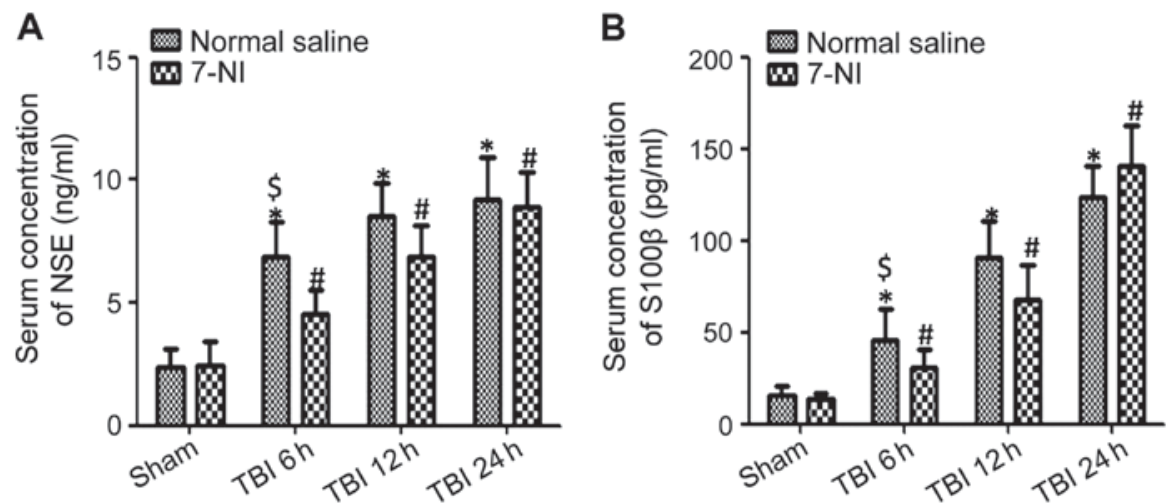

Figure 1. Levels of NSE and S100 $\beta$ in serum after different treatments: (A) Changes in NSE level after TBI in each group; (B) comparison of changes in S100 $\beta$ level after TBI. " $\mathrm{P}<0.05$, comparing the TBI group with the sham operation group in the normal saline treatment group; ${ }^{\text {}} \mathrm{P}<0.05$ comparing TBI group with the sham operation group in the 7-NI treatment group; ${ }^{\text {P }}<0.05$ comparing the normal saline treatment group with 7-NI treatment group at the same time-point. NSE, neuron-specific enolase; TBI, traumatic brain injury; 7-NI, 7-nitroindazole.
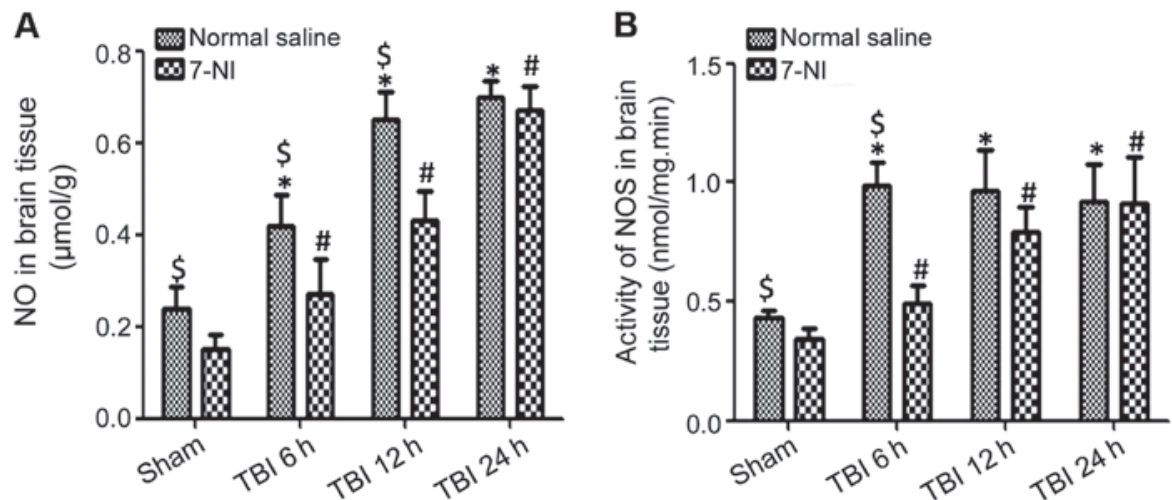

Figure 2. NO level and NOS activity in the brain tissues after different treatments: (A) Comparison of NO level in brain tissues after TBI in each group; (B) comparison of NOS activities in brain tissues after TBI in each group. ${ }^{*} \mathrm{P}<0.05$, comparing the TBI group with the sham operation group in the normal saline treatment group; ${ }^{*} \mathrm{P}<0.05$ comparing TBI group with the sham operation group in the 7-NI treatment group; ${ }^{5} \mathrm{P}<0.05$ comparing the normal saline treatment group with the 7-NI treatment group at the same time-point. NO, nitric oxide; NOS, nitric oxide synthase; TBI, traumatic brain injury; 7-NI, 7-nitroindazole.

NSE protein level after injury at each time-point was higher than the sham operation group $(\mathrm{P}<0.05)$. At $6 \mathrm{~h}$ after injury, NSE protein level in the 7-NI treatment group was significantly lower than that in the normal saline treatment group $(\mathrm{P}<0.05)$. At 12 and $24 \mathrm{~h}$ after injury time-points, there were no significant differences in the NSE levels between the 7-NI treatment group and the normal saline treatment group ( $\mathrm{P}>0.05)$ (Fig. 1).

S100 $\beta$ level after TBI in the normal saline treatment group and the 7-NI treatment group was gradually increased over time and reached a peak at $24 \mathrm{~h}$, and $S 100 \beta$ level after injury in two groups at each time-point was higher than the sham operation group $(\mathrm{P}<0.05)$. At $6 \mathrm{~h}$ after injury, $\mathrm{S} 100 \beta$ level in the 7-NI treatment group were significantly lower than that in the normal saline treated group $(\mathrm{P}<0.05)$. At 12 and $24 \mathrm{~h}$ after injury time-points, there was no significant difference in the S100 $\beta$ levels between the 7-NI treatment group and the normal saline treatment group $(\mathrm{P}>0.05)$ (Fig. 1).

Changes in NO content and NOS activity in brain tissue. NO level in the brain tissue after TBI in the normal saline treatment group and the 7-NI treatment group increased gradually over time and peaked at $24 \mathrm{~h}$. NO level in two groups after injury at each time-point was higher than the sham operation group $(\mathrm{P}<0.05)$. NO contents in brain tissue in the 7-NI treatment group were significantly lower in the sham operation group at 6 and $12 \mathrm{~h}$ after injury, compared to the normal saline treatment group $(\mathrm{P}<0.05)$. At $24 \mathrm{~h}$ after injury time-point, the difference in NO level between the 7-NI treatment group and normal saline treatment group was not statistically significant (P>0.05) (Fig. 2).

The NOS activity in brain tissue after TBI in the normal saline treatment group peaked at $6 \mathrm{~h}$ and then gradually decreased, but at 12 and $24 \mathrm{~h}$ time-points, the NOS activity in the normal saline treatment group was higher than that of the sham operation group $(\mathrm{P}<0.05)$. The NOS activity in brain after TBI in the 7-NI treatment group gradually increased over time and peaked at $24 \mathrm{~h}$ after injury. NOS activity in brain after injury at each time-point was higher in the 7-NI treatment group $(\mathrm{P}<0.05)$. In the sham operation group and at $6 \mathrm{~h}$ after injury, the NOS in the 7-NI treatment group was significantly lower than that in the normal saline treatment group $(\mathrm{P}<0.05)$. At 12 and $24 \mathrm{~h}$ after injury, there was no significant difference in NOS activity between the 7-NI treatment group and the normal saline treatment group ( $\mathrm{P}>0.05)$ (Fig. 2). 

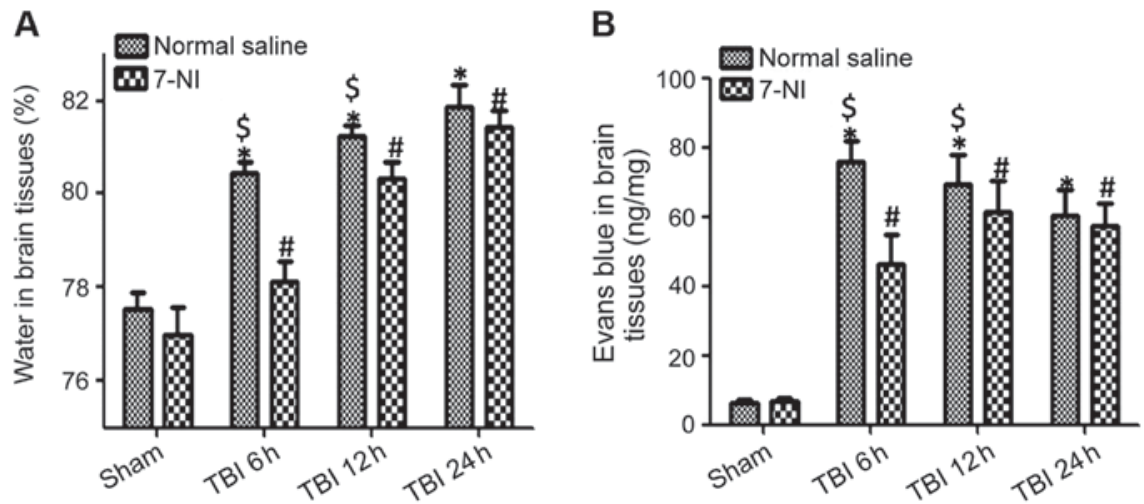

Figure 3. Contents of water and EB in the brain tissues after different treatments: (A) Comparison of water content in brain tissue after TBI in each group; (B) comparison of EB content in brain tissue after TBI in each group. ${ }^{*} \mathrm{P}<0.05$ comparing the TBI group with the sham operation group in the normal saline treatment group; ${ }^{\#} \mathrm{P}<0.05$ comparing the TBI group with the sham operation group in the 7-NI treatment group; ${ }^{\$} \mathrm{P}<0.05$ comparing the normal saline treatment group and the 7-NI treatment group at the same time-point. EB, Evans blue; TBI, traumatic brain injury; 7-NI, 7-nitroindazole.
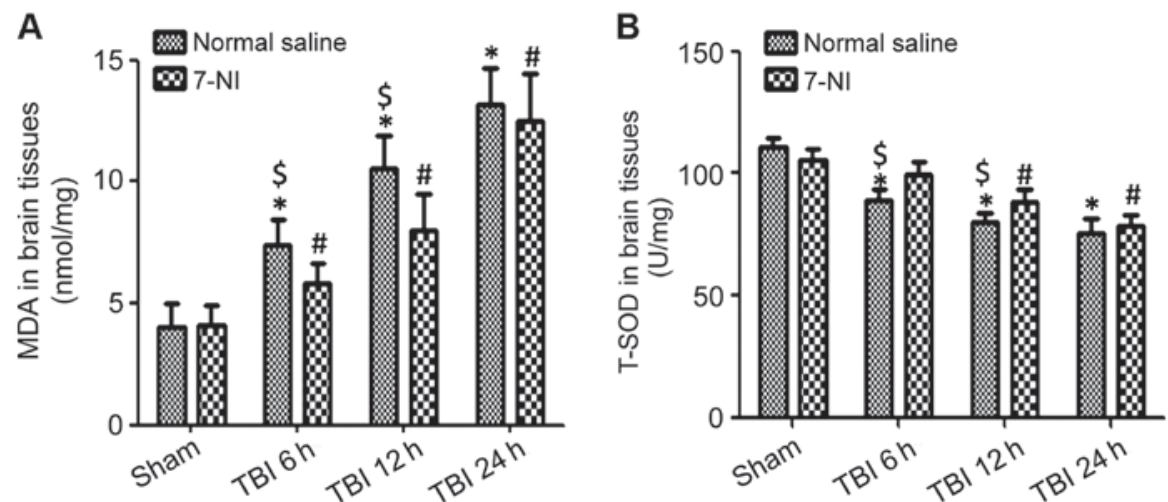

Figure 4. Levels of MDA and T-SOD in the brain tissues after different treatments: (A) Comparison of MDA level in the brain after TBI in each group; (B) comparison of T-SOD level in brain after TBI in each group. ${ }^{\text {" }} \mathrm{P}<0.05$ comparing the TBI group with the sham operation group in the normal saline treatment group; ${ }^{~} \mathrm{P}<0.05$ comparing TBI group with the sham operation group in the 7-NI treatment group; ${ }^{{ }^{\mathrm{P}}} \mathrm{P}<0.05$ comparing the normal saline treatment group and the 7-NI treatment group at the same time-point. MDA, malondialdehyde; TBI, traumatic brain injury; T-SOD, total superoxide dismutase; 7-NI, 7-nitroindazole.

Changes in water content and EB content in brain tissue. The water content in the brain after TBI in the normal saline treatment group and the 7-NI treatment group increased gradually over time and reached a peak at $24 \mathrm{~h}$. Water content in brain tissue after injury in two groups at each time-point was higher than that in the sham operation group $(\mathrm{P}<0.01)$. At 6 and $12 \mathrm{~h}$ after injury, brain tissue water content in the 7-NI treatment group was significantly lower than that of the normal saline treatment group $(\mathrm{P}<0.01)$. At $24 \mathrm{~h}$ after injury, there was no significant difference in brain water content between the 7-NI treatment group and the normal saline treatment group (P>0.05) (Fig. 3).

The EB content in brain tissue after TBI in the normal saline treatment group peaked at $6 \mathrm{~h}$ and then decreased gradually, but at 12 and $24 \mathrm{~h}$ time-points, EB content in the brain tissue was higher than the sham operation group $(\mathrm{P}<0.01)$. In the 7-NI treatment group, the EB content in brain after TBI reached a peak at $12 \mathrm{~h}$ after injury, but the EB content in brain after injury at 6 and $24 \mathrm{~h}$ time-points was higher than the sham operation group $(\mathrm{P}<0.01)$. At $6 \mathrm{~h}$ after injury, the EB content in the brain tissue in the 7-NI treatment group was significantly lower than that in the normal saline treatment group $(\mathrm{P}<0.01)$.
At 12 and $24 \mathrm{~h}$ after injury, there was no significant difference in EB content between the 7-NI treatment group and the normal saline treatment group ( $\mathrm{P}>0.05)$ (Fig. 3).

Changes in MDA and T-SOD levels. MDA content in brain tissue in the normal saline treatment group and the 7-NI TBI treatment group gradually increased over time and peaked at $24 \mathrm{~h}$. MDA content in brain tissue after injury in two groups at each time-point was higher than the sham operation group $(\mathrm{P}<0.05)$. At 6 and $12 \mathrm{~h}$ after injury, the MDA in the 7-NI treatment group was significantly lower than that in the normal saline treatment group $(\mathrm{P}<0.05)$. At $24 \mathrm{~h}$ after injury, there was no significant difference in MDA content between the 7-NI treatment group and the normal saline treatment group (P>0.05) (Fig. 4).

T-SOD content in brain tissue after TBI in the normal saline treatment group and the 7-NI treatment group decreased gradually over time and bottomed at $24 \mathrm{~h}$. T-SOD content in brain tissue at each time-point in the normal saline treatment group after injury was lower than that in the sham operation group $(\mathrm{P}<0.01)$. There was no significant difference in T-SOD content in brain after injury at $6 \mathrm{~h}$ time-point between the 


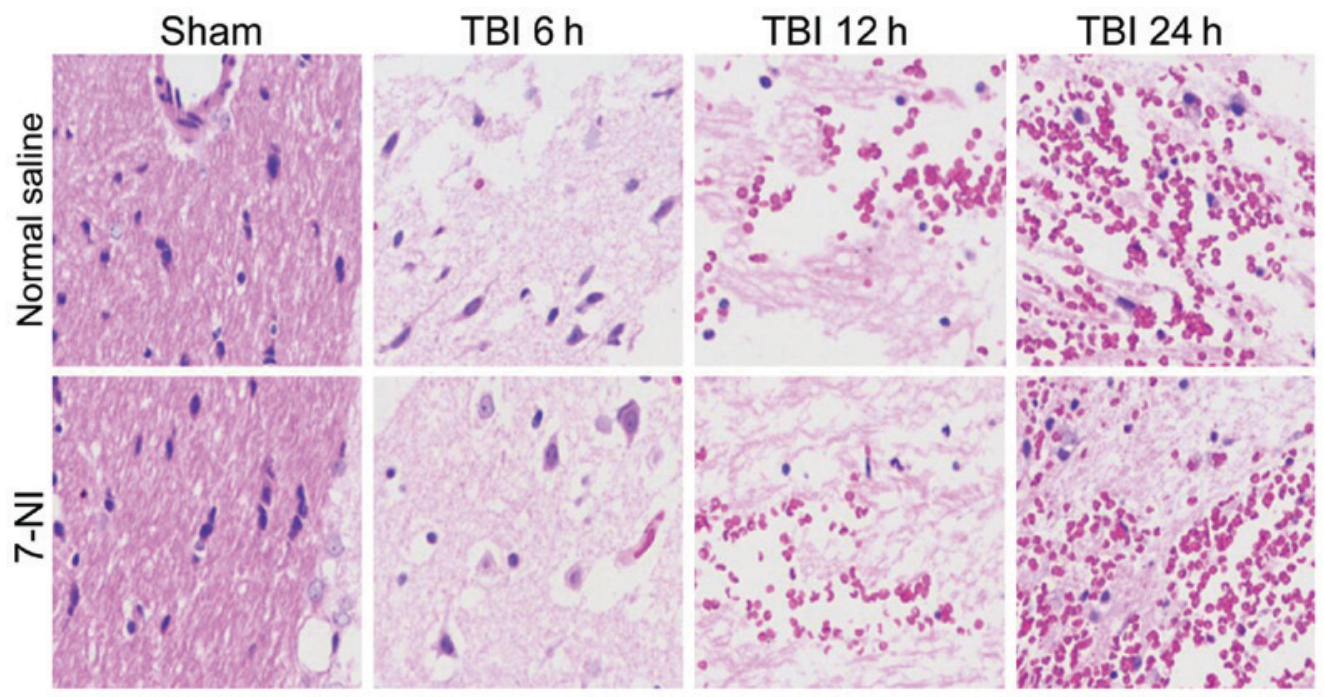

Figure 5. Observation and comparison of H\&E staining results in the brain tissue after TBI in each group. H\&E, hematoxylin and eosin; TBI, traumatic brain injury.

7-NI treatment group and the sham operation group $(\mathrm{P}<0.05)$ T-SOD level in brain tissue at 12 and $24 \mathrm{~h}$ after injury was significantly lower than that in the sham operation group $(\mathrm{P}<0.01)$. At 6 and $12 \mathrm{~h}$ after injury, the T-SOD level in the 7-NI treatment group was significantly higher than that in the normal saline treatment group $(\mathrm{P}<0.05)$. At $24 \mathrm{~h}$ after injury time-point, there was no significant difference in T-SOD level between the 7-NI treatment group and the normal saline treatment group (Fig. 4).

$H \& E$ staining. The brain tissue structure in the sham operation group was complete, the nerve cells were morphologically normal and were arranged uniformly and compactly. The cytoplasm was abundant, the nucleolus was clear and visible, and there was no tissue edema and hemorrhage. Additionally, no inflammatory cell infiltration was detected after TBI. Cortical structure integrity was destroyed, the nerve nucleus showed pyknosis, the neutrophils were under infiltration, the capillary was bleeding, which gradually became serious over time. Brain injury was aggravated considerably at $24 \mathrm{~h}$ time-point. At $6 \mathrm{~h}$ after TBI, the severity of brain injury in the 7-NI treatment group was suggestively less than that in the normal saline treatment group. At 12 and $24 \mathrm{~h}$ time-points, there was no significant difference in severity of brain injury between the two groups (Fig. 5).

\section{Discussion}

Numerous studies have shown that the nNOS-mediated NO is involved in pathological injury mechanism in early TBI $(5,6)$. The application of nNOS inhibitor 7-NI, in early stage after injury, can effectively reduce the impact of the NOS activity inside the brain, reduce $\mathrm{Ca}^{2+}$ overload and moderate the severity of brain tissue edema. Therefore, it can play a role in brain protection (7). NSE and S100 $\beta$ are located in neurons and glial cells and under normal circumstances they cannot pass through the BBB. After TBI, the BBB can be damaged or its permeability may be altered, therefore NSE and S100 $\beta$ levels can increase quickly $(8,9)$. This can be taken as a sensitive indicator to reflect the severity of TBI and judge prognosis $(8,9)$.

Our results showed that the application of 7-NI one hour after TBI could significantly decrease NSE and S100 $\beta$ levels in rats after injury. The complex pathophysiological process after TBI and its precise regulatory mechanism has not been fully understood, however, it is assumed that the process of brain injury after TBI can be divided into primary brain injury and secondary brain injury. The primary brain injury occur during early injury and is irreversible. Secondary brain injuries can occur with events such as increased NOS activity, massive release of NO, cerebral edema, BBB permeability alteration, lipid peroxidation and apoptosis (10-12). All these have been shown to be involved in the process of pathological injury after TBI and are closely related to nerve injury (10-12). We tried to assess whether 7-NI can play the role of the brain protector by regulating secondary brain injury pathophysiological processes, thereby reducing NSE and S100 $\beta$ levels after injury.

Earlier studies showed that early application of 7-NI after TBI could significantly reduce the NOS activity in brain at injured side (7). Our study found that early application of 7-NI after injury could significantly reduce the NO content and NOS activity at injured tissue at 6 and $12 \mathrm{~h}$ after injury, and 7-NI effect would disappear $24 \mathrm{~h}$ after injury. Prior studies showed that the occurrence of encephaledema following brain injury could cause the physiopathologic process of increased intracranial pressure, even brain herniation and aggravated brain injury, which could lead to the death of neurons and glial cells (13). BBB structural and functional alterations have been shown to be closely related to the encephaledema. An increase in BBB permeability after TBI can cause the release of NSE and S100 $\beta$ into the cerebrospinal fluid (14). Our results revealed that 7-NI significantly reduced the water content and EB content in brain at 6 and $12 \mathrm{~h}$ after TBI. MDA is the final product of peroxidasic reactions on lipids in mitochondria, which can directly measure the biological lipid oxidation level. T-SOD is not only an important biological oxidase in the body, but also the primary substance for scavenging free radicals 
in vivo. Therefore, MDA and T-SOD are often used as indicators to reflect brain oxidative stress after brain injury $(15,16)$. We investigated whether 7-NI could reduce NSE and S100 $\beta$ levels after TBI by affecting MDA and T-SOD levels in brain and decreasing oxidative stress-induced neuronal cell death. Our results showed that 7-NI reduced MDA level in brain tissue at 6 and $12 \mathrm{~h}$ after TBI, but at $24 \mathrm{~h}$, this effect disappeared. Additionally, 7-NI increased T-SOD in brain at $6 \mathrm{~h}$ after TBI, but had no impact on T-SOD level in brain at 12 and 24 h. Finally, H\&E staining results showed that 7-NI brain protection role mainly occurred at $6 \mathrm{~h}$ after injury.

We concluded that early application of 7-NI after TBI can protect the brain and reduce the levels of NSE and S100 $\beta$ by reducing the NO and NOS activity in the brain, reducing the severity of encephaledema, reducing $\mathrm{BBB}$ permeability, reducing the MDA contents in the brain tissues and increasing T-SOD level. We believe that early inhibition of nNOS activity after injury can be considered as the new direction in TBI treatment. Changes in NSE and S100 $\beta$ levels are well consistent with the above corresponding indicators, and therefore changes in the NSE and S100 $\beta$ levels can reflect the TBI treatment effects and may offer diagnostic value to a certain extent.

\section{References}

1. Rosenfeld JV, Maas AI, Bragge P, Morganti-Kossmann MC, Manley GT and Gruen RL: Early management of severe traumatic brain injury. Lancet 380: 1088-1098, 2012.

2. Wada K, Chatzipanteli K, Busto R and Dietrich WD: Effects of L-NAME and 7-NI on NOS catalytic activity and behavioral outcome after traumatic brain injury in the rat. J Neurotrauma 16: 203-212, 1999.

3. Berger RP, Beers SR, Richichi R, Wiesman D and Adelson PD: Serum biomarker concentrations and outcome after pediatric traumatic brain injury. J Neurotrauma 24: 1793-1801, 2007.

4. Fukushima M, Lee SM, Moro N, Hovda DA and Sutton RL: Metabolic and histologic effects of sodium pyruvate treatment in the rat after cortical contusion injury. J Neurotrauma 26: $1095-1110,2009$.
5. Wada K, Chatzipanteli K, Busto R and Dietrich WD: Role of nitric oxide in traumatic brain injury in the rat. J Neurosurg 89: 807-818, 1998.

6. Khan M, Dhammu TS, Matsuda F, Annamalai B, Dhindsa TS, Singh I and Singh AK: Targeting the nNOS/peroxynitrite/calpain system to confer neuroprotection and aid functional recovery in a mouse model of TBI. Brain Res 1630: 159-170, 2016.

7. Liu K, Yan M, Zheng X and Yang Y: The dynamic detection of NO during the ischemic postconditioning against global cerebral ischemia/reperfusion injury. Nitric Oxide 38: 17-25, 2014.

8. Ondruschka B, Pohlers D, Sommer G, Schober K, Teupser D, Franke H and Dressler J: S100B and NSE as useful postmortem biochemical markers of traumatic brain injury in autopsy cases. J Neurotrauma 30: 1862-1871, 2013.

9. Böhmer AE, Oses JP, Schmidt AP, Perón CS, Krebs CL, Oppitz PP, D'Avila TT, Souza DO, Portela LV and Stefani MA: Neuron-specific enolase, S100B, and glial fibrillary acidic protein levels as outcome predictors in patients with severe traumatic brain injury. Neurosurgery 68: 1624-1630, discussion 1630-1631, 2011.

10. Kochanek PM, Jackson TC, Ferguson NM, Carlson SW, Simon DW, Brockman EC, Ji J, Bayır H, Poloyac SM, Wagner AK, et al: Emerging therapies in traumatic brain injury. Semin Neurol 35: 83-100, 2015

11. Leker RR and Shohami E: Cerebral ischemia and trauma different etiologies yet similar mechanisms: neuroprotective opportunities. Brain Res Brain Res Rev 39: 55-73, 2002.

12. Laskowski RA, Creed JA and Raghupathi R: Pathophysiology of mild TBI: implications for altered signaling pathways. In: Brain Neurotrauma: Molecular,Neuropsychological, and Rehabilitation Aspects. Kobeissy FH (ed). CRC Press/Taylor \& Francis, Boca Raton, FL, 2015.

13. Marmarou A: A review of progress in understanding the pathophysiology and treatment of brain edema. Neurosurg Focus 22: E1,2007.

14. Murillo-Cabezas F, Muñoz-Sánchez MA, Rincón-Ferrari MD, Martín-Rodríguez JF, Amaya-Villar R, García-Gómez S and León-Carrión J: The prognostic value of the temporal course of S100beta protein in post-acute severe brain injury: a prospective and observational study. Brain Inj 24: 609-619, 2010.

15. Webster KM, Wright DK, Sun M, Semple BD, Ozturk E, Stein DG, O'Brien TJ and Shultz SR: Progesterone treatment reduces neuroinflammation, oxidative stress and brain damage and improves long-term outcomes in a rat model of repeated mild traumatic brain injury. J Neuroinflammation 12: 238, 2015.

16. Cojocaru IM, Cojocaru M, Sapira V and Ionescu A: Evaluation of oxidative stress in patients with acute ischemic stroke. Rom J Intern Med 51: 97-106, 2013. 